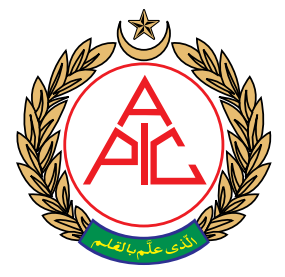

\title{
Epigastric pain after intravenous administration of oxytocin in patients undergoing lower segment cesarean section: A quasi experimental study comparing intravenous bolus with infusion technique
}

\author{
Ali Kashif ${ }^{1}$, Rizwana Bashir Kiani ${ }^{1}$, Syed Muhammad Asad Shabbir ${ }^{1}$, \\ Tariq Mahmood ${ }^{1}$, Ghulam Sabir ${ }^{2}$, Noor-e-Fatima ${ }^{3}$, \\ Waseem Ahmad Khan ${ }^{1}$
}

\author{
${ }^{1}$ PNS Shifa, DHA, Main \\ Korangi Road، Clifton, Karachi, \\ (Pakistan) \\ ${ }^{2} \mathrm{CMH}$ Hyderabad (Pakistan) \\ ${ }^{3}$ Allama Iqbal Medical College, \\ Lahore (Pakistan) \\ Correspondence: Dr Ali Kashif \\ PNS Shifa, DHA, Main Korangi \\ Road، Clifton, Karachi, \\ (Pakistan) \\ E-mail: kashif.doctor@gmail. \\ com; Phone: 03025481824 \\ Received: 20 February 2019; \\ Reviewed: 4, 16 March, 25 \\ June, 9 September, 2, 25 \\ November, 10 December \\ 2019, 7 January 2020; \\ Revised: 19 June, 10 August, \\ 29 September, 1 November \\ 2019, 6 January 2020; \\ Accepted: 10 January 2020
}

\begin{abstract}
Aim: To compare the frequency of epigastric pain and uterotonic effect of an equivalent dose of oxytocin administered as an intravenous bolus versus intravenous infusion during elective LSCS under spinal anesthesia.

Methodology: We recruited 98 parturients undergoing elective LSCS under spinal anesthesia for this prospective quasi experimental study and divided them into two groups. Group-A received 5 IU of oxytocin as bolus intravenous (IV) injection in $5 \mathrm{sec}$ (bolus group, $n=48$ ), and Group-B (infusion group, $n=50$ ) received 5 IU of oxytocin as an infusion over $5 \mathrm{~min}$. Any complaint of epigastric pain by the patients was noted and its frequency was compared between the two groups. The uterine tone was assessed as adequate or inadequate by an obstetrician. The data were entered into SPSS version 22. Patient demographic data were analyzed with independent samples T-test and the study data were analyzed with Chi-square test and presented as n (\%). $p<0.05$ was considered statistically significant.
\end{abstract}

Results: Epigastric pain was noted in 25 (52.03\%) out of 48 parturients in Group-A and $15(30 \%)$ out of 50 in Group-B ( $p=0.026)$. There was no significant difference in the uterotonic effect of oxytocin between the two groups $(p=0.736)$.

Conclusion: We conclude that oxytocin infusion is associated with lower frequency of epigastric pain in elective LSCS when compared to intravenous bolus of an equivalent dose of oxytocin, However, the effect on uterine contractions was adequate with both methods.

Citation: Kashif A, Kiani RB, Shabbir SMA, Mahmood T, Sabir G, Fatima NE, Khan WA. Epigastric pain after intravenous administration of oxytocin in patients undergoing lower segment cesarean section: A quasi experimental study comparing intravenous bolus with infusion technique. Anaesth pain intensive care 2020;24(1):50-54. DOI: https://doi.org/10.35975/apic.v24i1.1225

\section{INTRODUCTION}

Lower segment cesarean section (LSCS) is one of the most common obstetric procedures performed. ${ }^{1}$ Its number has increased in recent years because of various reasons. ${ }^{2}$ It is performed mostly under regional anesthesia; spinal anesthesia (SA) is the commonest. ${ }^{3}$ After delivery of the baby and clamping of the umbilical cord, oxytocin 5-10 international units (IU) is given intravenously (IV) in a bolus. It is administered for uterine contraction and to reduce uterine bleeding, which can occur due to uterine 
atony. Oxytocin, an uterotonic agent, is the mainstay of treatment for this uterine atony. Various regimens of oxytocin have been used during LSCS, with some desired (uterotonic) and some unwanted effects. ${ }^{4,5}$ Rapid injection of oxytocin produces various adverse effects, which include tachycardia, hypotension, ST depression in ECG, myocardial ischemia, nausea, vomiting, epigastric pain, chest pain, headache and flushing. ${ }^{6-11}$ Epigastric pain is also an established side effect of oxytocin, ${ }^{12-14}$ but there is a dearth of studies in this regard, especially during LSCS. There are several studies that compared oxytocin bolus and infusion during LSCS regarding hemodynamic side effects of oxytocin. These studies showed relatively less frequent adverse hemodynamic changes with oxytocin infusion. ${ }^{5,10}$ None of these studies threw light on epigastric pain.

We carried out this study to compare the effect of an equivalent dose of oxytocin administered either as an intravenous bolus or in infusion on the frequency of epigastric pain as well as uterotonic effects during elective LSCS under SA.

\section{METHODOLOGY}

This quasi experimental study was carried out at Department of Anesthesia \& Intensive Care, PNS Shifa (naval hospital) Karachi, from September 01, 2018 to December 31,2018. Approval from the hospital ethics committee was taken. Based on a previous study, sample size of 98 was calculated, with $95 \%$ confidence interval and $80 \%$ power. ${ }^{5} 98$ parturients scheduled for elective LSCS under SA, were selected by using nonprobability convenience sampling technique. Preanesthetic assessment of all the patients was carried out and informed consent was taken. Included in the study were ASA II pregnant women aged 18-45 years undergoing elective LSCS under SA. Patients with placenta previa, placenta accreta, diabetes mellitus, hypertension, pre-eclampsia and eclampsia, multiple gestations, polyhydramnios, known cardiac disease and hemoglobin less than $10 \mathrm{~g} / \mathrm{dl}$ were excluded.

Patients were instructed to avoid solid food for $8 \mathrm{~h}$ and allowed to drink plain water up to $2 \mathrm{~h}$ before the operation. After arriving in the operating room, an IV line was established with $18 \mathrm{G}$ cannula. During the preparation and administration of SA, patients were co-loaded with 1 L of Lactated Ringer's solution. All patients were premedicated with metoclopramide 10 $\mathrm{mg}$ and ranitidine $50 \mathrm{mg}$ IV. Baseline mean arterial pressure (MAP) was recorded before administering SA.

Patients were divided into two groups using computergenerated numbers. Group A $(\mathrm{n}=48)$ received 5 IU of oxytocin, diluted in $5 \mathrm{ml}$ of normal saline, as a bolus over $5 \mathrm{sec}$ and Group B $(\mathrm{n}=50)$ received an infusion of $5 \mathrm{IU}$ of oxytocin over $5 \mathrm{~min}$. The infusion was prepared by dissolving $5 \mathrm{IU}$ oxytocin in $15 \mathrm{ml}$ normal saline and was infused using a syringe pump.

SA was administered in the sitting position at L3/4 intervertebral space using 25G Quincke spinal needle keeping bevel of the needle on the lateral side. SA was performed by an anesthetist who was not involved in the study. Hyperbaric bupivacaine $0.75 \%(1.5 \mathrm{ml})$ was injected intrathecally. After spinal injection, all the patients were placed supine with left lateral uterine displacement using a wedge. Surgery was started once the sensory block to T6 level to pinprick was confirmed. All the routine parameters (ECG, heart rate, $\mathrm{SpO}_{2}$ and NIBP) were monitored. Mean blood pressure was kept within $20 \%$ of baseline values using phenylephrine $50 \mu \mathrm{g}$ bolus on as and when required basis.

After delivery, once the umbilical cord was clamped, oxytocin was injected as a bolus in Group-A, and infused in Group-B. Study period started from the time of the start of oxytocin injection and it continued for a further $10 \mathrm{~min} .{ }^{5}$ Patients were observed for any complaint of epigastric pain during this period. Mean arterial pressure was measured at 1-min interval for up to $5 \mathrm{~min}$, then at 7 and $10 \mathrm{~min}$ and kept within $20 \%$ of baseline levels as mentioned earlier. Uterine tone was assessed by the same obstetrician for all cases and described as adequate or inadequate. Oxytocin 5 IU $\mathrm{i} / \mathrm{v}$ was given as rescue medication if requested by the gynecologist on account of inadequate contraction of the uterus.

\section{Statistical analysis:}

Patients' demographic data are presented as mean \pm $\mathrm{SD}$ and analyzed with independent samples T-test using SPSS version 22. Study data were analyzed with Chi-square test by using SPSS version 22 and presented as $\mathrm{n}(\%) . \mathrm{p}<0.05$ was considered statistically significant.

\section{RESULTS}

This study was done on a total of 98 patients who were divided into two groups. There were 48 patients in Group- $A$, the bolus group and 50 patients in Group-B, the infusion group. Patient's characteristics were comparable in the two groups as shown in Table 1.

In Group-A, 25 patients developed epigastric pain as compared to 15 patients in Group-B. The difference between the two groups regarding epigastric pain was statistically significant $(\mathrm{p}<0.05)$. There was an insignificant difference between the two groups regarding the adequacy of the uterine contraction and the requirement of rescue medication; 3 vs. 4 patients in Group-A vs. Group-B respectively (Table 2). 
Table 1: Patient's demographic profile $($ Mean \pm SD)

\begin{tabular}{|c|c|c|c|c|}
\hline \multicolumn{2}{|c|}{ Parameters } & Group-A(n 48) & Group-B (n 50) & p-value \\
\hline \multicolumn{2}{|c|}{ Age $(y)$} & $26.95 \pm 3.99$ & $27.48 \pm 4.08$ & 0.52 \\
\hline \multicolumn{2}{|c|}{ Height (cm) } & $156.58 \pm 8.15$ & $157.94 \pm 7.68$ & 0.39 \\
\hline \multicolumn{2}{|c|}{ Weight (kg) } & $69.08 \pm 12.98$ & $71.48 \pm 12.59$ & 0.35 \\
\hline \multicolumn{2}{|c|}{ Baseline MAP $(\mathrm{mmHg})$} & $81.14 \pm 9.76$ & $81.86 \pm 7.67$ & 0.68 \\
\hline \multicolumn{2}{|c|}{ Pre-op Hb (g/dl) } & $11.03 \pm 0.94$ & $11.17 \pm 0.82$ & 0.44 \\
\hline \multicolumn{2}{|c|}{ Phenylephrine $(\mu g)$} & $37.50 \pm 34.97$ & $38.00 \pm 37.19$ & 0.94 \\
\hline \multirow{2}{*}{ Parity } & Primigravida & 16 & 12 & \\
\hline & Multigravida & 32 & 38 & \\
\hline
\end{tabular}

Table 2: Comparative frequency of epigastric pain and adequacy of uterine contractions

\begin{tabular}{l|c|c|c} 
Parameter & $\begin{array}{c}\text { Group-A } \\
\text { (n 48) }\end{array}$ & $\begin{array}{c}\text { Group-B } \\
\text { (n 50) }\end{array}$ & p-value \\
\hline Epigastric pain & $25(52.03)$ & $15(30)$ & 0.026 \\
\hline $\begin{array}{l}\text { Uterine contraction } \\
\text { Adequate }\end{array}$ & $\begin{array}{c}4(93.75) \\
\text { Inadequate }\end{array}$ & $\begin{array}{c}46(92) \\
4(8)\end{array}$ & 0.736 \\
\hline
\end{tabular}

Data presented as $n(\%)$

\section{DISCUSSION}

LSCS is the commonest obstetrical surgical procedure, performed mostly under SA. ${ }^{1}$ Parturients undergoing LSCS are at higher risk of postpartum hemorrhage (PPH). ${ }^{10} \mathrm{PPH}$ is one of the main causes of maternal mortality. Its incidence reaches up to almost $10 \%$ of all deliveries, whether spontaneous or operative. Uterotonics are the mainstay of management of $\mathrm{PPH}$ and oxytocin is the most commonly employed uterotonic agent. Incidence of PPH can be decreased by almost $40 \%$ by use of oxytocin. ${ }^{15}$ Despite its frequent use, there have been discussions about its correct dose and method of administration. ${ }^{5}$

Uterine oxytocin receptors increase in number during pregnancy and are highest at term. Because the term uterus is more sensitive to oxytocin, its lower dose can be effective and safe as compared to higher dose. ${ }^{9}$ Different effects, doses and methods of administration of oxytocin have been studied in LSCS under SA. 5 IU has been preferred dose as recommended by Confidential Enquiry into Maternal Deaths (CEMD) ${ }^{16}$ and also supported by Pinder et al. ${ }^{6}$ Butwick et al. studied the efficacy of various doses of oxytocin in LSCS. They concluded that lower doses (0.5-3 IU) are as effective as 5 IU to achieve adequate uterine contraction. ${ }^{17}$ Thomas and colleagues further established that dose of 5 IU administered over a period of $5 \mathrm{~min}$, results in greater haemodynamic stability. ${ }^{5}$ Rapid injections of large doses of oxytocin cause some serious side effects, such as, nausea, vomiting, hypotension, chest pain, myocardial ischemia, ST-T segment changes, headache, flushing, and convulsions. ${ }^{18}$ Our study finds that there is a lower frequency of epigastric pain in the infusion group as compared to bolus group. 25 parturients in the bolus group complained of pain as compared to 15 in the infusion group. When Yusuf et al. compared 5 and 10 IU boluses of oxytocin, only 1 out of 55 patients developed epigastric from each group. ${ }^{11}$ This is in high contrast to our findings. Widmer et al. compared carbetocin with oxytocin. They studied patients from 23 hospitals in 10 different countries. Out of about 14000 of their patients who received oxytocin, only 56 developed abdominal pain. ${ }^{19}$ Again these results are grossly different from our results. This difference could be due to a small sample size and population belonging to different ethnic and cultural background.

Our results are in agreement with Thomas et al. who concluded that oxytocin bolus should be used cautiously in patients with unstable cardiovascular status and reassured about uterotonic effects of oxytocin when infused over 5 min. ${ }^{5}$ Same conclusion was drawn by another study, which found that administration of oxytocin intravenous infusion is better than the same dose given as intravenous bolus in elective LSCS to produce adequate uterine contraction and is associated with less adverse hemodynamic changes. ${ }^{10}$

As far as the uterotonic effect of oxytocin is concerned, no difference was found between bolus and infusion group. Only 3 patients from the bolus group and 4 from the infusion group needed rescue medication. Therefore, it can be said that slower oxytocin injections are not only clinically effective but are associated with a lower frequency of epigastric pain.

\section{LIMITATIONS}

There are certain limitations to this study. Randomized controlled trials with larger sample size are required to establish the exact relationship between oxytocin and epigastric pain in LSCS. Sample populations from different, ethnic, cultural and socioeconomic backgrounds need to be studied as well.

\section{CONCLUSION}

We conclude that during elective lower segment cesarean sections, the use of oxytocin as an infusion 
original research

is a better than a bolus of the same dose given intravenously, as it is associated with fewer complaints of epigastric pain, while providing adequate uterine contraction.

Conflict of interest: Nil declared by the authors

Authors' contribution:

AK: Concept, conduction of study, literature search, manuscript writing, statistical analysis

RBK: Conduction of study

SMAS: Statistical analysis

TM, WAK: Manuscript editing

GS: Literature search

NF: Manuscript typing and language and grammatical review

\section{REFERENCES}

1. Mussarat N, Qureshi S, Roohi M. Lower segment caesarean section (LSCS); indications and complications at teaching hospital, Faisalabad. Professional Med J. 2013;20(6):91623. [Free Full Text]

2. Karim F, Ghazi A, Ali T, Aslam R, Afreen $\mathrm{U}$, Romana F. Trends and determinants of caesarean section. J Surg Pak. 2011;16(1):22-7. [Free Full Text]

3. Sirajuddin M, Abbas N, Murtaza G, Naqvi SMN. Common complaints associated with caesarean section during spinal anesthesia. Ann Abbasi Shaheed Hosp Karachi Med Dent Coll. 2013;18(1):33-7. [Free Full Text]

4. Langesaeter $E$, Rosseland $L A$ and Stubhaug A. Haemodynamic effects of repeated doses of oxytocin during caesarean delivery in healthy parturients. $\mathrm{Br} J$ Anaesth. 2009;103(2):260-2. [PubMed] DOl: 10.1093/bja/aep137

5. Thomas JS, Koh SH, Cooper GM. Haemodynamic effects of oxytocin given as i.v. bolus or infusion on women undergoing caesarean section. $\mathrm{Br} J$ Anaesth. 2007;98(1):116-9. [PubMed] DOI: 10.1093/bja/ael302

6. Pinder AJ, Dresner M, Calow C, Shorten GD, O'Riordan J, Johnson R. Haemodynamic changes caused by oxytocin during caesarean section under spinal anaesthesia. Int J Obstet Anesth. 2002;11:156-9. [PubMed] DOI: $10.1054 /$ ijoa.2002.0970

7. Langesaeter $E$, Rosseland $L A$ and Stubhaug A. Haemodynamic effects of oxytocin during caesarean delivery. Int J Gynaecol Obstet. 2006;95:467. [PubMed] DOI: 10.1016/i. ijgo.2006.05.032

8. Archer TL, Knape K, Liles D, Wheeler
AS, Carter B. The haemodynamics of oxytocin and other vasoactive agents during neuraxial anaesthesia for caesarean delivery: findings in six cases. Int $\mathrm{J}$ Obstet Anesth. 2008;17:247-54. [PubMed] DOl: 10.1016/i.ijoa.2008.03.003

9. Devikarani D, Harsoor S. Are we using right dose of oxytocin? Indian J Anaesth. 2010;54:371-3. [PubMed] DOI: $\underline{10.4103 / 0019-5049.71020}$

10. Bhattacharya S, Ghosh S, Ray D, Mallik S, Laha A. Oxytocin administration during caesarean delivery: Randomized controlled trial to compare intravenous bolus with intravenous infusion regimen. J Anaesthesiol Clin Pharmacol. 2013;29:32-5. [PubMed] DOl: 10.4103/0970-9185.105790

11. Yusuf MM, Nwasor EO, Mohammed RI. Is 5 IU bolus of oxytocin as effective as $10 \mathrm{IU}$ bolus for control of bleeding during caesarean section under spinal anaesthesia? Arch Med Surg. 2017;2:7-11. DOl: 10.4103/ archms.archms $32 \quad 17$

12. Osilla EV, Sharma S. Oxytocin. [Updated 2019 Mar 2]. In: StatPearls [Internet]. Treasure Island (FL): StatPearls Publishing; 2019 Jan-. Available from: https://www.ncbi. nlm.nih.gov/books/NBK507848/ [Accessed on 18 June 2019]

13. Oxytocin (Intravenous Route, Intramuscular Route) Side Effects Mayo Clinic [Internet]. Mayoclinic.org. 2019. Available from: https://www. mayoclinic.org/drugs-supplements/ oxytocin-intravenous-routeintramuscular-route/side-effects/drg20065254 [Accessed on 18 June 2019]
14. Injection G, Pitocin B. Common Side Effects of Pitocin (Oxytocin Injection) Drug Center- RxList [Internet]. RxList. 2019. Available from: https://www. rxlist.com/pitocin-side-effects-druqcenter.htm [Accessed on 18 June 2019]

15. Nordström L, Fogelstam K, Fridman G, Larsson A, Rydhstroem H. Routine oxytocin in the third stage of labour: $A$ placebo controlled randomized trial. $\mathrm{Br}$ J Obstet Gynaecol. 1997;104(7):7816. [PubMed] DOI: 10.1111/i.14710528.1997.tb12020.x

16. Bolton TJ, Randall K, Yentis SM. Effect of the confidential enquiries into maternal deaths on the use of Syntocinon at caesarean section in the UK. Anaesthesia. 2003:58:2779. [PubMed] DOl: 10.1046/i.13652044.2003.30435.x

17. Butwick AJ, Coleman L, Cohen SE, Riley ET, Carvalho B. Minimum effective bolus dose of oxytocin during elective caesarean delivery. Br J Anaesth. 2010;104(3):338-43. [PubMed] DOI: 10.1093/bja/aeq004

18. Svanstrom MC, Biber $B$, Hanes $M$, Johansson G, Naslund U, Balfors EM. Signs of myocardial ischemia after injection of oxytocin: a randomized double-blind comparison of oxytocin and methylergometrine during caesarean section. $\mathrm{Br} J$ Anaesth. 2008;100(5):683-9. [PubMed] DOI: 10.1093/bja/aen071

19. Widmer $M$, Piaggio $G$, Nguyen $\mathrm{TMH}$, Osoti A, Owa 00, Misra S, et al. Heat-Stable Carbetocin versus Oxytocin to prevent haemorrhage after vaginal birth. $\mathrm{N}$ Engl $\mathrm{J}$ Med. 2018;379(8):743-52. [PubMed] DOI: 10.1056/NEJMoa1805489 